\title{
Aqueous processing of boron carbide powders
}

\author{
Jingxian ZHANG, ${ }^{\dagger}$ Dongliang JIANG and Qingling LIN \\ The State Key Laboratory of High Performance Ceramics and Superfine Structure, \\ Shanghai Institute of Ceramics, 1295 Dingxi Road, Shanghai 200050, China
}

The present study was performed to determine suitable processing conditions to obtain optimized boron carbide slurries for gelcasting. We examined how dispersant, pH and other factors function in boron carbide slurries. The effect of the dispersant on the slurry stability was characterized in terms of zeta potential, sedimentation, and rheology measurements. Subsequently, the optimum conditions for the preparation of stable slurries with high solid content were determined. Gelcasting was used to consolidate the slurries. The effect of monomers on the slurry properties was studied. The properties of green and sintered $\mathrm{B}_{4} \mathrm{C}$ samples were also investigated.

(02008 The Ceramic Society of Japan. All rights reserved.

Key-words: Boron carbide, Slurry, Rheology, Gelcasting, Mechanical properties

[Received January 12, 2008; Accepted May 15, 2008]

\section{Introduction}

Because of their unique physical and chemical properties such as ultrahigh hardness, low density, excellent chemical stability and high neutron absorption capability, boron carbide $\left(\mathrm{B}_{4} \mathrm{C}\right)$ materials have found a wide application in aerospace, nuclear energy and high-temperature thermoelectric conversion, blasting, polishing and more. ${ }^{1)}$ However, their widespread applications have been restricted mainly due to their low mechanical reliability, high machining cost as well as poor sinterability due to a low self-diffusion coefficient. Several additives have been investigated in order to promote the sinterability of $\mathrm{B}_{4} \mathrm{C}$. The addition of carbon has been found to be effective in improving the densification of $\mathrm{B}_{4} \mathrm{C}$. ${ }^{2}$

Gelcasting is an attractive near-net-shape ceramic-forming techniquewhich can effectively increase materials reliability and lower the manufacturing costs of complex-shaped ceramic parts. ${ }^{3)-5)}$ The process involves preparation of high solid loading ceramic slurries with monomers, catalysts and initiators. Gelling is initiated after the slurry is cast in a mold. The organic component can serve as carbon source in the subsequent sintering process. In gelcasting process, particle dispersion is often the limiting factor, affecting both rheology and homogeneity of the suspensions. ${ }^{6)}$

Up to now, there are no reports about the dispersion and gelcasting of $\mathrm{B}_{4} \mathrm{C}$. In this study, the dispersion of $\mathrm{B}_{4} \mathrm{C}$ slurries was studied in term of zeta potential, sedimentation and rheological tests. The properties of gelcasted $\mathrm{B}_{4} \mathrm{C}$ samples were further studied.

\section{Experimental procedure}

The powder used was boron carbide (Mudanjiang Jingangzuan Boron Carbide Co., Ltd.) with the average particle size as 0.93 $\mu \mathrm{m}$ and a specific surface area as $10.78 \mathrm{~m}^{2} / \mathrm{g}$. Tetramethylammonium hydroxide (TMAH) was used as the dispersant. Aqueous suspensions were prepared by adding ceramic powders to deionized water in the presence of different amount of dispersant. The $\mathrm{pH}$ of suspensions was adjusted by $\mathrm{HNO}_{3}$ and $\mathrm{NaOH}$.
In the process of gelcasting, $\mathrm{N}, \mathrm{N}$-dimethyl acrylamide (DMAA) and N, N'-methylenebisacrylamide (MBAM) were applied as organic monomers for polymerization. 2, 2'-azobis [2(imidazolin-2-yl) propane] dihydrochloride(AZIP-2HCl) was used as the initiator. In our study, the ratio of AZIP to DMAA is fixed at 1:130 by mass after screening. To avoid the possible coagulation of the suspensions, a dilute AZIP solution (5 mass\%) was used as the initiator source. The gel casting process was well addressed in literature. $\left.{ }^{6}\right)$ Typically, An aqueous solution containing 12 mass\% of DMAA and MBAM (Aldrich) in 13/1 ratio in the presence TMAH as the dispersant was used as the dispersing medium. The slurries were prepared by adding $\mathrm{B}_{4} \mathrm{C}$ powder to the premix solutions and ball milled for $24 \mathrm{~h}$. Then the suspension was transferred to a flask followed by the addition of the initiator (AZIP). After degassing and casting, the moulds were put in water bath at $80^{\circ} \mathrm{C}$ for $30 \mathrm{~min}$ in order to gel the system. The gelled pieces were carefully dried to avoid cracking.

\subsection{Zeta potential test}

Zeta potential of the $\mathrm{B}_{4} \mathrm{C}$ particles was measured through Zetaplus (Brookhaven Instruments Corporation). Ceramic suspensions $(0.01 \mathrm{vol} \%)$ were prepared in the absence and presence of dispersant at various pHs. The ionic strength of each slurry was adjusted with $0.001 \mathrm{M} \mathrm{KCl}$ solution.

\subsection{Settling experiments}

Sedimentation measurements were carried out on $10 \mathrm{vol} \%$ $\mathrm{B}_{4} \mathrm{C}$ suspensions. After $\mathrm{pH}$ adjustment, suspensions were pored into graded tubes. Reading of the sedimentation volume was recorded during $7 \mathrm{~d}$.

\subsection{Rheological measurements}

The suspensions were placed in milling jars and roll-milled for $24 \mathrm{~h}$ before analysis. Apparent viscosity of the suspensions under different shear rate was examined under steady shear conditions by ascending and descending shear rate ramps respectively using a stress controlled rheometry (SR-5 Rheomeric scientific instrument company, USA.).

Corresponding author: J. Zhang; E-mail: jxzhang@ mail.sic.ac.cn 


\subsection{Microstructure, mechanical and other proper- ties}

After gelcasting and drying, binder burnout for all samples was carried out at $800^{\circ} \mathrm{C}$ for $2 \mathrm{~h}$ in vacuum. Sintering was performed in Ar atmosphere and hold for $1 \mathrm{~h}$ for all samples. Tests of flexural strength were performed by three point bending from specimens of size $3 \times 4 \times 36 \mathrm{~mm}^{3}$. The microstructure of all samples was observed by SEM. The composition of $\mathrm{B}_{4} \mathrm{C}$ powder and the as-sintered $\mathrm{B}_{4} \mathrm{C}$ samples was also determined by chemical analysis.

\section{Results and discussions}

\subsection{Surface properties of $B_{4} C$}

The zeta potential curves of $\mathrm{B}_{4} \mathrm{C}$ powder are shown in Fig. 1. In the absence of TMAH, $\mathrm{B}_{4} \mathrm{C}$ particle is negatively charged in the $\mathrm{pH}$ range studied (from $\mathrm{pH} 1.7$ to 12 ). When the $\mathrm{pH}$ was increased, the zeta potential decreased and the minimum value appeared around $\mathrm{pH}$ 9. Further increase in $\mathrm{pH}$ will result in an upward trend of this curve. Therefore, the $\mathrm{B}_{4} \mathrm{C}$ particles can be stabilized around $\mathrm{pH} 9$ by electro-static force. After the addition of TMAH, an increase in zeta potential was observed. The dissociation of TMAH in aqueous solution can be described as the following ${ }^{7)}$

$$
\left(\mathrm{CH}_{4}\right)_{4} \mathrm{~N}(\mathrm{OH}) \rightarrow\left(\mathrm{CH}_{4}\right)_{4} \mathrm{~N}^{+}+\mathrm{OH}^{-}
$$

As TMAH is positive-charged in water, the association of TMAH on negatively charged $\mathrm{B}_{4} \mathrm{C}$ particle surface is highly possible. As shown in Fig. 1, in the presence of TMAH, the $\mathrm{pH}_{\text {IEP }}$ of $\mathrm{B}_{4} \mathrm{C}$ powder shifts slightly toward high $\mathrm{pH}$, this might be due to the adsorption of TMAH. However, the zeta potential did not show a significant change, and the $\mathrm{pH}_{\text {IEP }}$ just increase slightly, so it is proposed that TMAH is mainly served as a $\mathrm{pH}$ adjusting agent, and the adsorption of TMAH on $\mathrm{B}_{4} \mathrm{C}$ particle surface is not so high, similar to the case for $\mathrm{SiC}^{8)}$

The stability of $\mathrm{B}_{4} \mathrm{C}$ suspensions is evaluated from change of sedimentation volume as a function of $\mathrm{pH}$ and time. As shown in Fig. 2, the stability of $\mathrm{B}_{4} \mathrm{C}$ suspension can be achieved in the $\mathrm{pH}$ range from 5.5 to 8.5. At lower $(\mathrm{pH}<4)$ or higher $(\mathrm{pH}>9)$ $\mathrm{pH}$ region, an increased sedimentation is induced, which might be due to the low surface charge of $\mathrm{B}_{4} \mathrm{C}$ particles (see Fig. 1).

The influence of TMAH on the stability of $\mathrm{B}_{4} \mathrm{C}$ suspensions was further characterized in term of apparent viscosity, see Fig. 3. With the addition of TMAH, the viscosity of $\mathrm{B}_{4} \mathrm{C}$ slurries initially decreased with the increase of TMAH up to the TMAH to $\mathrm{B}_{4} \mathrm{C}$ mass ratio of $5 \mathrm{mg} / \mathrm{g}$, reached a minimum point and

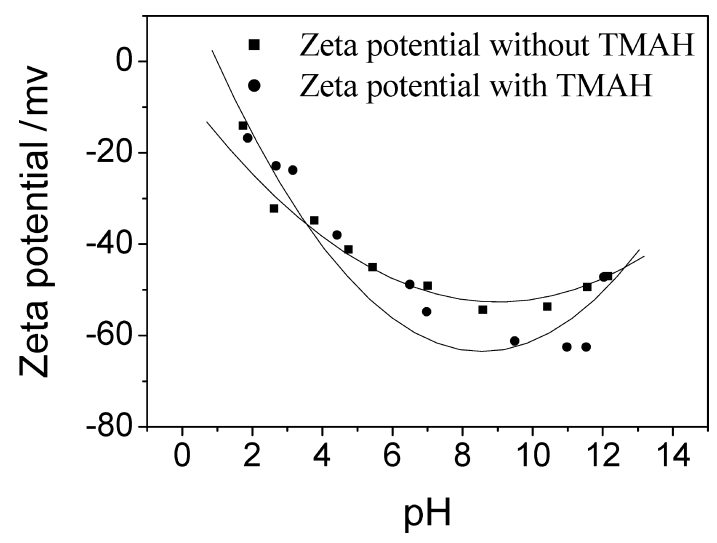

Fig. 1. Zeta potential of $\mathrm{B}_{4} \mathrm{C}$ powder.

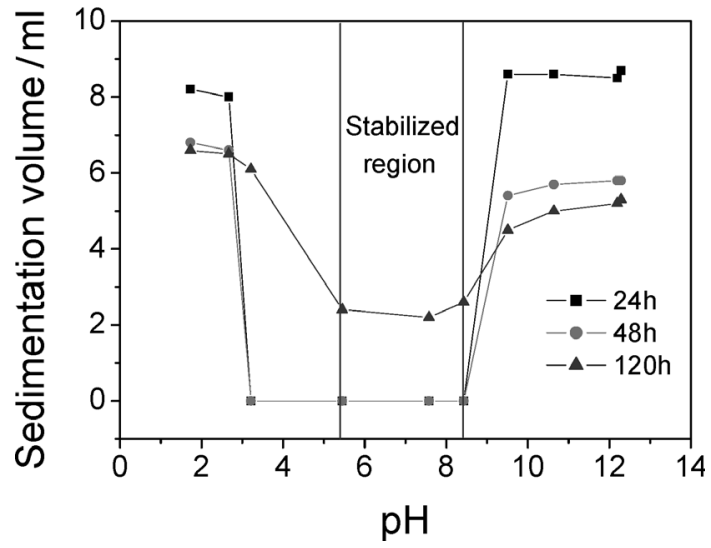

Fig. 2. Sedimentation test with $10 \mathrm{vol} \% \mathrm{~B}_{4} \mathrm{C}$ slurries.

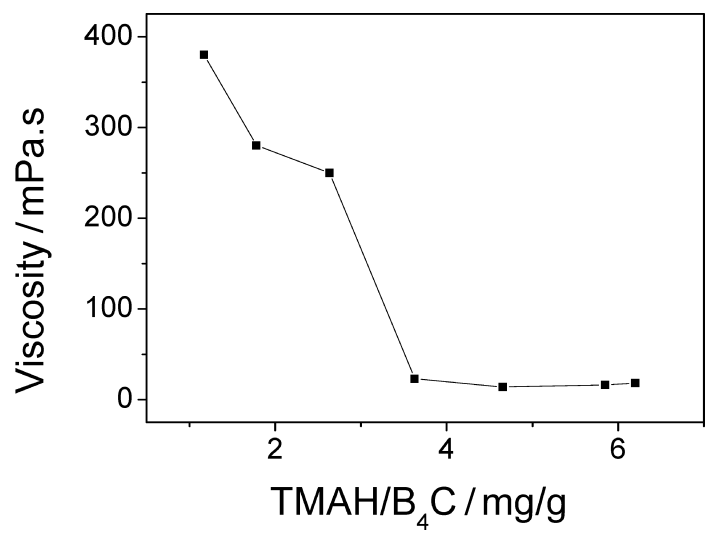

Fig. 3. Viscosity of $50 \mathrm{vol} \% \mathrm{~B}_{4} \mathrm{C}$ slurries (shear rate $350 \mathrm{~s}^{-1}$ ).

increased thereafter (the shear rate is $350 \mathrm{~s}^{-1}$ ). From Fig. 3, it can be concluded that TMAH could help to improve the slurry stability. This might be mainly due to the electrostatic force developed among $\mathrm{B}_{4} \mathrm{C}$ particles because an increase in surface charge density was resulted in the presence of TMAH, see Fig. 1. The optimal TMAH content can also be determined (at the TMAH/ $\mathrm{B}_{4} \mathrm{C}$ mass ratio of $\sim 5 \mathrm{mg} / \mathrm{g}$ ).

Subsequently, 57 vol\% $\mathrm{B}_{4} \mathrm{C}$ slurries were prepared around $\mathrm{pH}$ 7 with the TMAH/ ${ }_{4} \mathrm{C}$ mass ratio as $5 \mathrm{mg} / \mathrm{g}$. The rheological properties were shown in Fig. 4. $\mathrm{B}_{4} \mathrm{C}$ slurries exhibited a shear thickening behavior at higher shear rate $\left(>292 \mathrm{~s}^{-1}\right)$. A stable

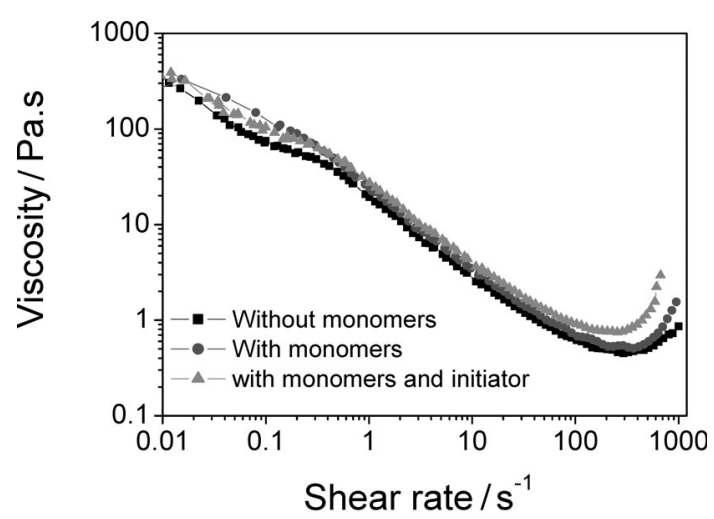

Fig. 4. Rheological properties of 57 vol $\% \mathrm{~B}_{4} \mathrm{C}$ slurries. 
suspension tends to behave as a pseudoplastic fluid with low viscosity at low shear rates which may suddenly increase at a critical shear rate: shear thickening (dilatancy). ${ }^{9}$ Figure 4 showed that $\mathrm{B}_{4} \mathrm{C}$ slurries were in well stabilized state. This can also be correlated to the zeta potential, sedimentation tests and would confirm that TMAH was effective for obtaining well stabilized $\mathrm{B}_{4} \mathrm{C}$ slurries.

After the addition of monomers, the slurry stability was also studied. The results are shown in Fig. 4. The addition of monomer and initiator showed very limited effect on the slurry stability. After degassing, the concentrated slurries showed good fluidity for the gelcasting process. After casting, gelation and drying, well-shaped green bodies were obtained. No obvious contraction and cracking was observed. The samples showed enough strength for demoulding and handling. The relative density of green samples was $64 \%$. The mechanical properties of green samples are high. This high strength comes from the crosslinked gel network, which adhered to $\mathrm{B}_{4} \mathrm{C}$ particles and bound them together. Pores with different sizes in the green bodies were also observed. The pore diameter distribution, obtained by $\mathrm{Hg}$ intrusion porosimetry, showed a monomodal distribution type with the peak around $156 \mathrm{~nm}$, see Fig. 5. Figure 5 confirmed a homogeneous microstructure of $\mathrm{B}_{4} \mathrm{C}$ green bodies by gelcasting.

The relative density of sintered samples at $2250^{\circ} \mathrm{C}$ was $91.6 \%$, similar to that shown in literature using $1-3$ mass $\% \mathrm{C}$ as the sintering additives and sintered at $2325^{\circ} \mathrm{C}$ ( the relative density is in the range of $90-91 \%) .{ }^{10}$ The fracture strength is $261 \pm 39 \mathrm{MPa}$. Schwetz et al reported the preparation of $\mathrm{B}_{4} \mathrm{C}$ ceramics using 4 mass\% carbon as the sintering additives, the relative density and flexural strength was $96.4 \%$ and $475 \mathrm{MPa}$ respectively after pressureless sintering at $2150^{\circ} \mathrm{C} .^{2)}$ However, this high carbon addition might have deleterious effects on the mechanical properties of $\mathrm{B}_{4} \mathrm{C}$ samples. ${ }^{11)}$ The low density in our study might be due to the lack of sintering additives. Table 1 showed the carbon content in the powder and sintered samples. A slight increase in carbon content was observed after sintering. This extra carbon might come from the monomers, which could

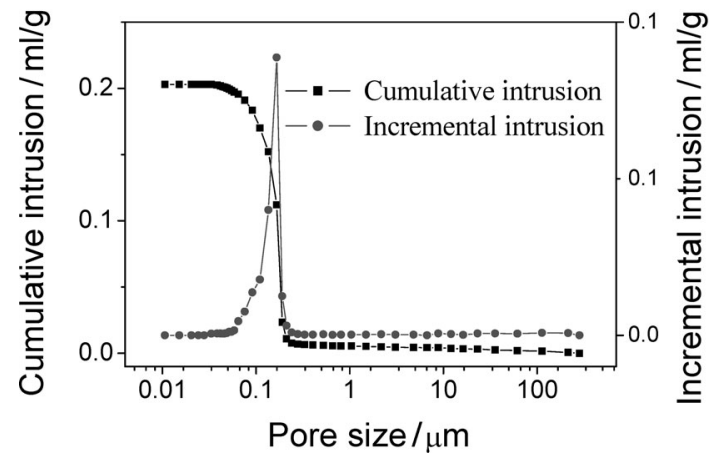

Fig. 5. Pore size distribution of $\mathrm{B}_{4} \mathrm{C}$ green samples.

Table 1. Composition of Starting Powder and as-Sintered $\mathrm{B}_{4} \mathrm{C}$ Samples

\begin{tabular}{ccc}
\hline Elements & \multicolumn{2}{c}{ Content (mass\%) } \\
\hline & $\mathrm{B}_{4} \mathrm{C}$ powder & $\mathrm{B}_{4} \mathrm{C}$ sintered sample \\
\cline { 2 - 3 } $\mathrm{C}$ & 23.54 & 24.23 \\
$\mathrm{~B}$ & 75.45 & 75.02 \\
$\mathrm{O}$ & 1.01 & 0.75 \\
\hline
\end{tabular}

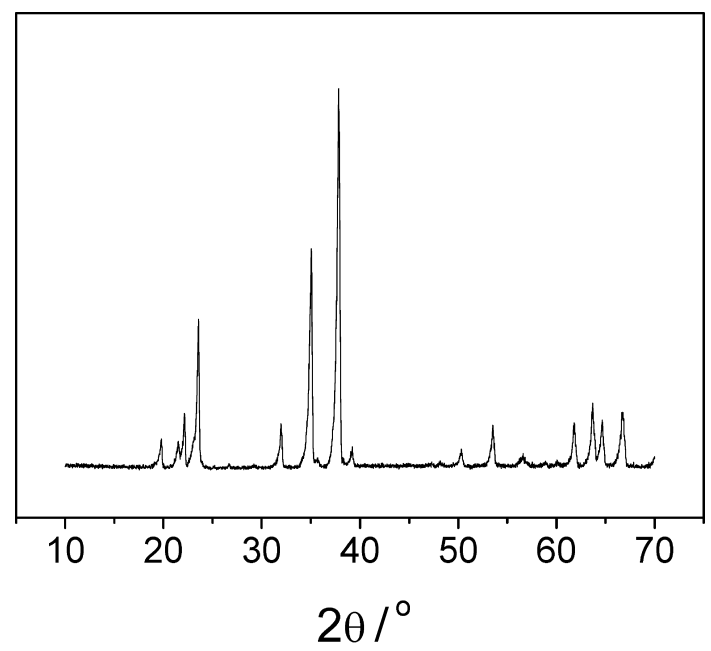

Fig. 6. XRD pattern of as sintered $\mathrm{B}_{4} \mathrm{C}$ samples.

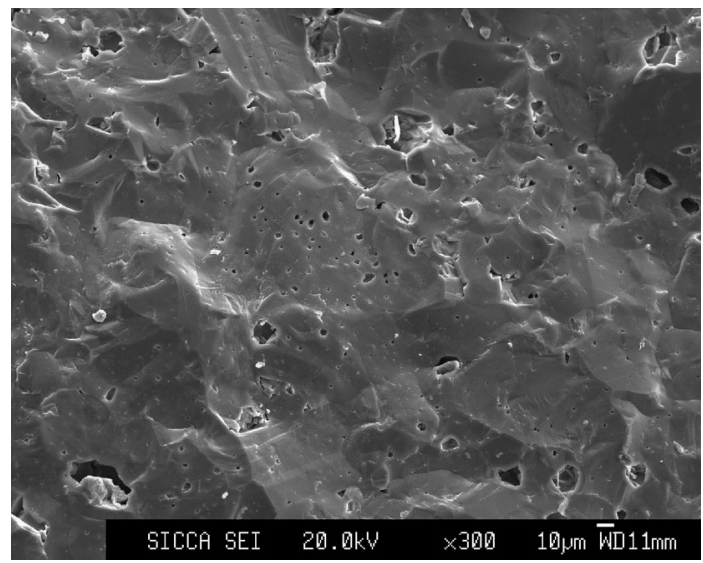

Fig. 7. Micrographs of as-sintered $\mathrm{B}_{4} \mathrm{C}$ samples.

not be removed completely from the samples after binder removal. However, the carbon content is too low for the densification process. The XRD patterns showed the pure phase of $\mathrm{B}_{4} \mathrm{C}$ according to PCPDFWIN Card No. 35-0798, Fig. 6. Micrographs of the fracture surface of $\mathrm{B}_{4} \mathrm{C}$ sintered samples are shown in Fig. 7. A transgranular fracture type is observed. The fracture surface shows the presence of both fine and large pores, in agreement with the relative density value. Up to now, no literature about the colloidal processing of $\mathrm{B}_{4} \mathrm{C}$ materials. Further study on the sintering and microstructure control is in process.

\section{Conclusions}

The stability of $\mathrm{B}_{4} \mathrm{C}$ powder in aqueous media was studied using TMAH as the dispersant. Zeta potential showed that $\mathrm{B}_{4} \mathrm{C}$ particles were negatively charged in the whole $\mathrm{pH}$ range investigated. Sedimentation test showed that $\mathrm{B}_{4} \mathrm{C}$ powder can be stabilized in the $\mathrm{pH}$ range of 5.5-8.5. Viscosity and rheological measurement showed that TMAH was effective for obtaining stable $\mathrm{B}_{4} \mathrm{C}$ slurries. After addition of monomers and imitators, the slurry stability was well kept and meets the requirement for gelcasting. The green samples exhibited a homogeneous microstructure with the relative density as high as $64 \%$. Results showed that TMAH is a good dispersant for the gelcasting of $\mathrm{B}_{4} \mathrm{C}$ ceramics. 
Acknowledgment This work was supported by the Shanghai Science and Technology Committee (No. 06JC14071).

\section{References}

1) W. C. Johnson, Am. Ceram. Soc. Bull., 80, 64-66 (2001).

2) K. A. Schwetz, L. S. Sigl and L. Pfau, J. Solid State Chem., 133, 68-76 (1997).

3) A. C. Young, O. O. Omatete, M. A. Janney and P. A. Menchhofer, J. Am. Ceram. Soc., 74, 612-681 (1991).

4) O. O. Omatete, M. A. Janney and R. A. Strehlow, Am. Ceram. Soc. Bull., 70, 1641-1649 (1991).

5) O. O. Omatete, M. A. Janney and S. D. Nunn, J. Eur. Ceram.
Soc., 17, 407-413 (1997).

6) M. A. Janney, O. O. Omatete, C. A. Walls, S. D. Nunn, R. J. Ogle and G. Westmoreland, J. Am. Ceram. Soc., 81, 581-591 (1998).

7) Z. P. Xie, J. T. Ma, Q. Xu, Y. Huang and Y.-B. Cheng, Ceram. Inter., 30, 219-224 (2004).

8) T. Zhang, Z. Q. Zhang, J. X. Zhang, D. L. Jiang and Q. L. Lin, Mater. Sci. \& Engineering A, 443, 257-261 (2007).

9) H. A. Barnes, J. Rheol., 33, 329-366 (1989).

10) T. K. Roy, C. Subramanian and A. K. Suri, Ceram. Inter., 32, 227-233 (2006).

11) F. Thévenot, J. Eur. Ceram. Soc., 6, 205-225 (1990). 